\title{
Fatores associados a resultados falso-negativos de exames citopatológicos do colo uterino
}

\author{
Factors associated with false-negative cervical cytopathological results \\ Rosana Franco ${ }^{1}$, Rita Goreti Amaral ${ }^{2}$, Eliana Borin Lopes Montemor ${ }^{3}$, \\ Douglas Munhoz Montis ${ }^{4}$, Sirlei Siani Morais ${ }^{5}$, Luiz Carlos Zeferino ${ }^{6}$
}

\section{RESUMO}

\begin{abstract}
Objetivo: verificar se, no escrutínio de rotina, fatores relacionados com a adequabilidade da amostra, padrão celular e critérios citomorfológicos estão associados a resultados falso-negativos (FN) dos exames citopatológicos. Métodos: trata-se de um estudo caso-controle, no qual o grupo de casos incluiu 100 esfregaços citopatológicos com um resultado FN que foi detectado pela sistemática de controle interno da qualidade com revisão rápida de $100 \%$. Para cada resultado FN detectado foram identificados, pelo mesmo citotécnico, dois esfregaços com um diagnóstico verdadeiro-positivo e este grupo foi considerado controle, totalizando uma casuística de 300 esfregaços. As variáveis analisadas foram estabelecidas de acordo com os critérios definidos para a análise da adequabilidade da amostra, padrão celular e critérios citomorfológicos. Os resultados foram avaliados por análise bivariada e regressão logística com critério de seleção de variáveis stepwise e expressos em OR (95\%). Resultados: o número de células atípicas, aspecto da cromatina nuclear, distribuição e apresentação de células atípicas no esfregaço apresentaram risco maior para resultados FN, com OR de 9,6; 4,2; 4,4 e 3,6, respectivamente. Processo inflamatório e presença de sangue no esfregaço mostraram também risco para os resultados FN. Conclusões: a maioria dos fatores associados à liberação de um resultado FN é dependente das condições e técnicas de coleta de material, pois, em grande parte, a lesão pode não estar adequadamente representada no esfregaço, e também fatores obscurecedores como sangue e processo inflamatório podem prejudicar a análise. Quanto às alterações citomorfológicas, cromatina fina foi a característica que apresentou maior risco para resultados FN.
\end{abstract}

PALAVRAS-CHAVE: Colo do útero/patologia; Neoplasias do colo uterino/diagnostico; Reações falso-negativas

\section{ABSTRACT}

Purpose: to evaluate whether factors related to the adequacy of the sample, cell pattern and cytomorphological criteria are associated with false-negative (FN) results of cervical cytopathology during routine examinations. Methods: this is a case-control study in which the study group included 100 cytopathologic smears with FN results detected during systematic internal quality control consisting of $100 \%$ rapid review. For each FN result detected, two smears with a true-positive diagnosis were identified by the same cytotechnician and these constituted the control group, making a total sample size of 300 smears. The variables were established in accordance with the criteria defined for the analysis of sample adequacy, cell pattern and cytomorphological analyzed criteria. The results were evaluated using bivariate analysis and logistic regression with stepwise variable selection criteria expressed in OR (95\%). Results: the number of atypical cells, the appearance of nuclear chromatin, and the distribution and presentation of atypical cells in the smear were the variables that showed the greatest risk for FN results with OR of 9.6, $4.2,4.4$, and 3.6, respectively. Inflammatory processes and the presence of blood in the smear were also identified as variables that influence the risk of FN results. Conclusions: the majority of the factors associated with FN results are dependent on the conditions and techniques of sample collection, since in the majority of cases, the lesion may not be adequately represented in the smear. Confounding factors such as blood and inflammatory processes may also impair analysis. With respect to cytomorphological alterations, thin chromatin strand was the variable that indicated the greatest risk of FN results.

KEYWORDS: Cervix/pathology; Uterine cervical neoplasms/diagnóstico; False negativereactions

Centro de Atenção Integral à Saúde da Mulher (Caism) da Universidade Estadual de Campinas - Unicamp - Campinas (Sp), Brasil.

1 Mestranda do Departamento de Tocoginecologia da Faculdade de Ciências Médicas da Universidade Estadual de Campinas - UNICAMP - Campinas (SP), Brasil.

2 Professora Doutora da Faculdade de Farmácia da Universidade Federal de Goiás - UFG - Goiânia (GO), Brasil.

3 Citologista do Laboratório de Citopatologia da Universidade Estadual de Campinas - UNICAMP - Campinas (SP), Brasil.

4 Citopatologista do Laboratório de Citopatologia da Universidade Estadual de Campinas - UNICAMP - Campinas (SP), Brasil.

5 Estatística do Departamento de Tocoginecologia da Faculdade de Ciências Médicas da Universidade Estadual de Campinas - UNICAMP - Campinas (SP), Brasil.

6 Professor Doutor do Departamento de Tocoginecologia da Faculdade de Ciências Médicas da Universidade Estadual de Campinas - UNICAMP - Campinas (SP), Brasil.

Correspondência: Luiz Carlos Zeferino

Rua Alexander Fleming, 101 - Cidade Universitária "Zeferino Vaz" - 13083-881 - Campinas-SP - Telefone: (19) 3788-7138; Fax: (19) 3788-8010 - e-mail: zeferino@caism.unicamp.br 


\section{Introdução}

O câncer de colo uterino é uma das mais freqüentes causas de óbito na população feminina da América Latina, onde as taxas de incidência são também uma das mais altas do mundo ${ }^{1}$. Em países onde os programas de rastreamento do câncer do colo uterino são bem estruturados observou-se, no entanto, redução significativa destas taxas ${ }^{2,3}$.

O exame citopatológico é universalmente utilizado para o rastreamento deste câncer, porém tem sido alvo de críticas devido às altas taxas de resultados falso-negativos $(\mathrm{FN})^{4,5}$. Os fatores associados com resultados FN têm sido explorados, porém continua sendo um desafio superá-los ou atenuar seus efeitos ${ }^{1,6}$.

O Sistema Bethesda ${ }^{7}$ inovou ao introduzir a análise da qualidade do esfregaço no laudo do exame citopatológico, valorizando a presença de sangue, processo inflamatório e artefatos de fixação como fatores relacionados com a qualidade do esfregaço. Ainda, fatores patológicos como a citólise e infecção microbiana podem interferir negativamente nas características do esfregaço ${ }^{8}$.

O desempenho diagnóstico do exame citopatológico está associado a erros de coleta, variabilidade na interpretação citomorfológica e erros no escrutínio microscópico ${ }^{5,9}$. Trata-se de rotina que exige concentração e comportamento meticuloso dos profissionais, de tal forma que é importante identificar fatores evitáveis ou que demandariam mais atenção pela maior possibilidade de apresentar resultado $\mathrm{FN}^{4}$. Além disso, a presença e características das células atipicas presentes no esfregaço estão relacionadas com taxa de diagnósticos corretos $^{4,10}$.

Portanto, o objetivo deste estudo foi analisar se, no escrutínio de rotina, fatores relacionados com a adequabilidade da amostra, padrão celular e critérios citomorfológicos estão associados a resultados FN dos exames citopatológicos.

\section{Métodos}

Este estudo foi aprovado pelo Comitê de Ética em Pesquisa da Faculdade de Ciências Médicas e realizado no Laboratório de Citopatologia do Caism/Unicamp, que analisa em média 25 mil esfregaços por mês. Os esfregaços incluídos no estudo eram de mulheres usuárias do Sistema Único de Saúde de Campinas e região, que se submeteram ao exame citopatológico (Papanicolaou) nos postos de saúde, usando a técnica convencional. Trata-se de um estudo caso-controle, em que o grupo de casos incluiu 100 esfregaços citopatológicos consecutivos que foram diagnosticados pelos citotécnicos, no escrutínio de rotina, com resultado FN de lesão intra-epitelial escamosa de baixo grau (LSIL) ou lesão intra-epitelial escamosa de alto grau (HSIL). Esses esfregaços com resultado FN foram detectados por meio da sistemática de controle interno da qualidade com revisão rápida de um minuto ${ }^{11}$. O grupo dos casos foi composto de 89 LSIL e 11 HSIL.

Para cada resultado FN incluído no grupo de casos, foram selecionados dois esfregaços com o mesmo diagnóstico neoplásico, porém, corretamente detectado pelo mesmo citotécnico responsável pelo diagnóstico de FN, ou seja, um diagnóstico verdadeiro-positivo (VP). Esta amostra foi considerada como grupo-controle e foi composta de 178 LSIL e 22 HSIL. Todos os esfregaços dos grupos de casos e controles foram numerados em ordem crescente, impossibilitando, desta forma, que os pesquisadores pudessem identificar quais eram os esfregaços FN e VP. Foram selecionados esfregaços do período entre março de 2004 e novembro de 2005.

Para se obter uma amostra mais homogênea optou-se por incluir apenas esfregaços com os resultados de LSIL e HSIL. Considerou-se que o diagnóstico de ASCUS apresenta limitações para atender aos objetivos deste estudo, devido à baixa concordância diagnóstica entre observadores ${ }^{12}$. Os diagnósticos relacionados às células glandulares, ainda que clinicamente importantes, são pouco freqüentes e, portanto, também não foram incluídos neste estudo ${ }^{13}$.

Todos os esfregaços foram revisados simultaneamente, em miscroscópio de duas cabeças, por dois citologistas. As variáveis analisadas relacionaram-se a adequabilidade da amostra, ao padrão celular e aos critérios citomorfológicos. Quanto à adequabilidade da amostra, foram analisadas fixação (satisfatória ou limitada), citólise (satisfatória ou limitada), processo inflamatório (obscurecimento parcial provocado pela quantidade de leucócitos, classificado como presente ou ausente), sangue (obscurecimento parcial provocado pela presença de hemácias, classificado como presente ou ausente), degeneração celular, células endocervicais e células metaplásicas (classificados como presentes ou ausentes). Quanto ao padrão celular, foram analisados número de células atípicas (até 50 ou mais de 50), tamanho das células atípicas (grandes ou pequenas), distribuição celular (parte da lâmina ou por toda lâmina) e apresentação celular (agrupadas-sincício ou isoladas). Quanto aos critérios citomorfológicos, foram analisados: aspecto da cromatina (fina ou granular), distribuição da cromatina (regular ou irregular), membrana nuclear 
(espessa-irregular ou lisa), hipercromatismo (moderado-acentuado ou discreto) e relação núcleo/citoplasma (moderada/acentuada ou discreta). Antes da revisão houve padronização dos conceitos para a interpretação dos critérios diagnósticos.

Para estimar a magnitude de associação de cada critério citomorfológico com o diagnóstico final foi utilizada a análise bivariada, sendo que os resultados foram expressos em valores de odds ratio (OR), com intervalo de confiança de $95 \%$. A análise de regressão logística (análise multivariada) com critério de seleção de variáveis stepwise foi usada para avaliar a interação entre as variáveis, sendo que os resultados foram expressos em valores $\mathrm{OR}$ com intervalo de confiança de $95 \%{ }^{14}$. A associação foi considerada estatisticamente significante quando o intervalo de confiança não incluiu o valor um. Quando uma das extremidades do intervalo de confiança foi um inteiro, a significância foi considerada limítrofe. As variáveis que apresentaram valores de OR e intervalos de confiança maiores do que um foram consideradas como fator de risco (promotoras) para resultados $\mathrm{FN}$, ao passo que aquelas que apresentaram valores abaixo de um foram consideradas como fator de proteção (protetoras) que evita resultados FN.

\section{Resultados}

O número de células atípicas, o aspecto da cromatina nuclear, a distribuição e a apresentação de células atípicas no esfregaço foram associados a risco maior para resultados FN. A presença de 50 ou menos células atípicas no esfregaço $(53 \%)$ foi o fator que apresentou maior risco para resultados FN, com OR de 9,6. Quando a distribuição das células atípicas foi apenas localizada (68\%), o OR para resultado FN foi de 4,4. A apresentação de células atípicas isoladas (62\%) também apresentou OR de 3,6 para resultados FN em comparação com apresentação de células agrupadas ou em sincício (Tabela 1).

Com relação aos critérios citomorfológicos, a cromatina com aspecto fino esteve presente em $80 \%$ dos resultados $\mathrm{FN}$, ao passo que foi observada em $48 \%$ dos VP, resultando em risco de 4,3. A hipercromasia discreta e membrana nuclear lisa apresentaram associação significativa, porém com menor valor de OR para resultados FN, 2,7 e 2,8, respectivamente. Dentre os fatores relacionados à adequabilidade da amostra, apenas a presença de sangue mostrou significância limítrofe (Tabela 1).

A Figura 1 representa os valores de OR e respectivos intervalos de confiança obtidos pela análise multivariada, sendo que apenas os inter- valos de confiança que não cruzam a linha vertical (valor um) foram considerados significativos. Até 50 células atípicas, cromatina fina e distribuição localizada de células atípicas apresentaram maior risco para os resultados $\mathrm{FN}$, com OR de 8,5, 4,0 e 3,0, respectivamente. Processo inflamatório e presença de sangue no esfregaço, apesar de menor magnitude, mostraram também risco para os resultados FN, com OR de 2,8 e 2,2, respectivamente. A presença de células metaplásicas foi o único fator investigado que esteve associado a OR menor do que um, sendo que a significância pode ser considerada limítrofe uma vez que o limite superior do intervalo de confiança foi 1,1 .

\section{Discussão}

Os resultados deste estudo mostraram que células atípicas em pequeno número, isoladas, presentes apenas em parte do esfregaço, presença de sangue e processo inflamatório são características de exames que mais freqüentemente estão associados a resultados FN no escrutínio citológico. Esses fatores estão relacionados às condições e técnicas de coleta de material para realização do exame citopatológico.

O baixo número de células atípicas tem sido descrito como fator associado a resultados FN no escrutínio citológico, assim como a presença de células atípicas localizadas e isoladas ${ }^{4,5}$. O presente estudo apresentou maior valor de OR para o baixo número de células atípicas, tanto na análise bivariada quanto na multivariada.

A presença de sangue e de processo inflamatório não tem sido sistematicamente associada com maior freqüência de resultados FN, porém nesse estudo a análise multivariada mostrou que são fatores que se associaram de maneira independente com maior risco para resultados $\mathrm{FN}^{6,7}$. É possivel que esse aparente conflito ocorra devido a diferenças no critério de avaliação da quantidade de sangue e intensidade do processo inflamatório, pois esses fatores comprometem a análise citológica ${ }^{6,7}$.

Neste estudo o exame citopatológico foi realizado pelo método convencional. O método de coleta em meio líquido tem sido apontado como uma alternativa para melhorar a adequabilidade da amostra, diminuir o número de esfregaços insatisfatórios e aumentar a percentagem de diagnóstico de lesões de alto grau ${ }^{15,16}$. Todavia, uma revisão sistemática recente, que analisou a qualidade dos estudos que compararam o desempenho da citologia convencional com a citologia em meio líquido, demonstrou que não houve diferença na proporção de esfregaços insatisfatórios e na detecção de lesões de alto 
Tabela 1 - Análise de fatores relacionados à adequabilidade da amostra, padrão celular e critérios citomorfológicos com os resultados falso-negativos (FN) e verdadeiro-positivos (VP) dos esfregaços cervicais.

\section{Grupo FN $(n=100)$}

$(\%)$
Grupo VP $(n=200)$

$(\%)$
OR IC (95\%)

(Análise bivariada)

Adequabilidade da amostra

Fixação

Limitada

Satisfatório

Citólise

Presente

Ausente

Processo inflamatório

Presente

Ausente

Sangue

Presente

Ausente

Degeneração

Presente

Ausente

Padrão celular

Células endocervicais

Presentes

Ausentes

Células metaplásicas

Presentes

Ausentes

Número de células atípicas

$$
\leq 50
$$

$>50$

Tamanho das células atípicas

Células pequenas

Células grandes

Apresentação celular

Isoladas

Agupadas/sincício

Distribuição celular

Parte da lâmina

Por toda lâmina

Critérios citomorfológicos

Distribuição da cromatina

Irregular

Regular

Aspecto da cromatina

Fina

Granular

Membrana nuclear

Lisa

Espessa//rregular

Hipercromasia

Discreta

Moderada/Acentuada

Relação núcleo/citoplasma

Discreta

Moderada/Acentuada
22,0

78,0

36,0

64,0

51,0

49,0

50,0

50,0

24,0

76,0

85,0

15,0

55,0

45,0

53,0

47,0

13,0

87,0

62,0

38,0

68,0

32,0

5,0

95,0

80,0

20,0

58,0

42,0

30,0

70,0

47,0

53,0
25,0

75,0

28,0

72,0

41,5

58,5

39,0

61,0

19,0

81,0

89,0

11,0

65,5

34,5

10,5

89,5

10,0

90,05

31,0

69,0

32,5

67,5

4,5

95,5

48,0

52,0

33,0

67,0

13,5

86,5

39,0

61,0
Total $(n=300)$

$0,8(0,5-1,5)$

228

92

208

134

166

128

172

62

238

263

37

186

114

74

226

33

267

124

176

133

167

286

176

124

124

176

57

243

125

175
$4,4(2,6-7,4)$

$1,1(0,4-3,5)$

$1,4(0,9-2,4)$

$1,5(0,9-2,4)$

$1,6(1,0-2,5)$

$1,3(0,8-2,4)$

$0,7(0,4-1,4)$

$0,6(0,4-1,1)$

$9,6(5,3-17,5)$

$1,3(0,6-2,8)$

$3,6(2,2-6,0)$

$4.23(2.2-8.3)$

$2,8(1,7-4,6)$

$2,7(1,52-5,0)$

$1,4(0,9-2,3)$

Rev Bras Ginecol Obstet. 2006; 28(8): 479-85 


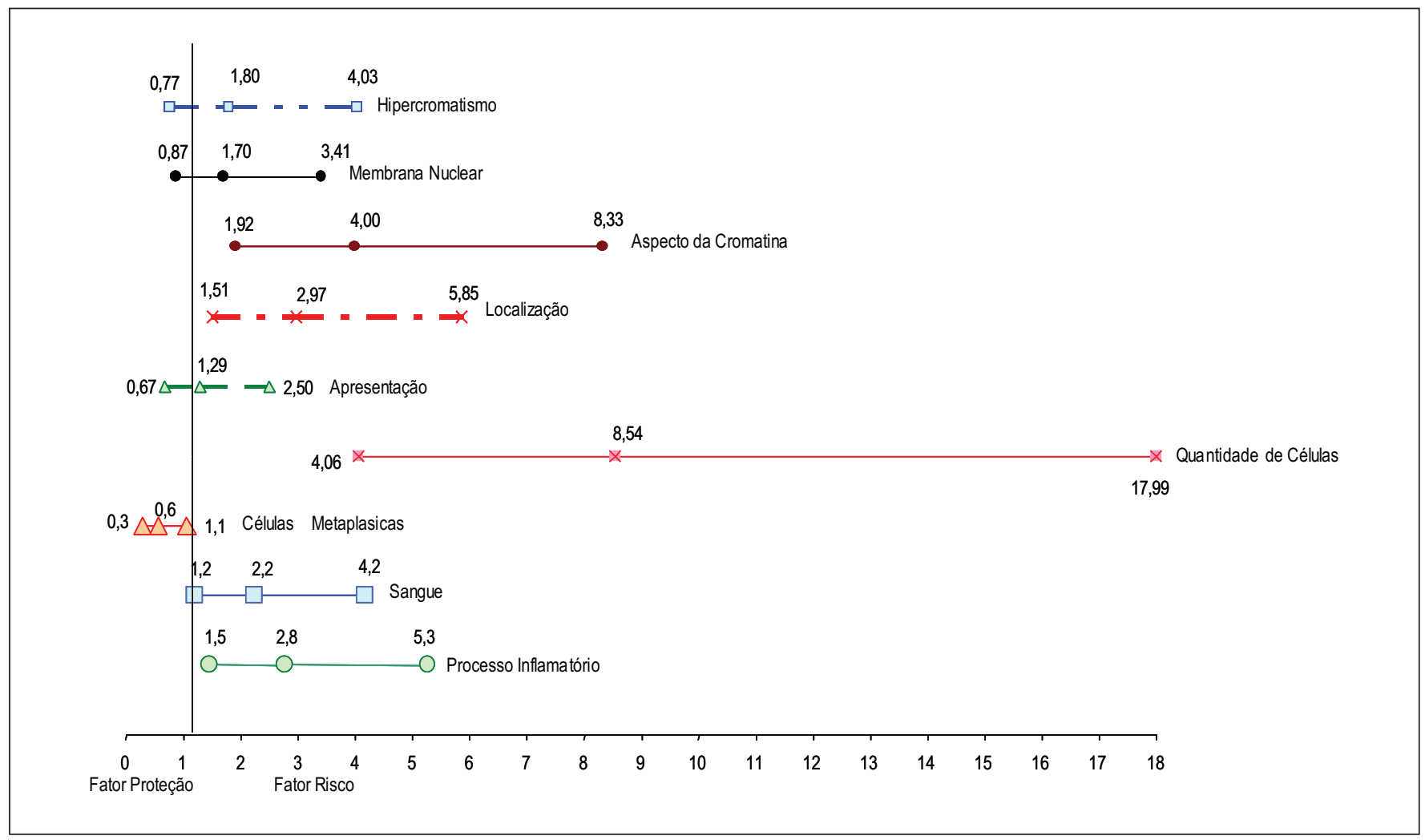

Figura 1 - Valores de odds ratio e respectivos intervalos de confiança dos fatores relacionados à adequabilidade da amostra, padrão celular e critérios citomorfológicos, obtidos por meio de análise multivariada.

grau entre os dois métodos. O que foi demostrado é que a maioria dos trabalhos avaliados apresentou alguma restrição metodológica ${ }^{17}$.

As diferentes técnicas de citologia em meio líquido descrevem com detalhes os procedimentos de coleta, que normalmente são seguidos pelos coletadores $^{18-20}$. A experiência tem mostrado que os profissionais não coletam material para o exame citopatológico convencional com o mesmo rigor e cuidado com que o fazem para o método em meio líquido. Essa suposição seria importante viés quando o desempenho entre essas técnicas é comparado ${ }^{17}$.

Outros fatores que podem contribuir com as elevadas taxas de resultados FN são os erros de escrutínio e de interpretação, que são dependentes dos fatores relacionados com a técnica de coleta da amostra ${ }^{1,9}$. É importante agregar a esta análise as características citomorfológicas, pois este estudo mostrou que células atípicas com cromatina fina, membrana nuclear lisa e discreta hipercromasia associaram-se a maior freqüência de resultados FN, na análise bivariada, em acordo com os achados de outros trabalhos ${ }^{4,5}$, com exceção para análise da membrana nuclear, que não foi uma variável abordada nos estudos citados. Na análise multivariada, apenas células atípicas com cromatina fina mostraram associação com resultados FN, o que se deve a fato de que são fatores que estão inter-relacionados ${ }^{21}$.

De fato, é esperado que essas alterações citomorfológicas mais discretas sejam menos freqüentemente detectadas no escrutinio de rotina ${ }^{4,5}$. $\mathrm{Na}$ interpretação citológica, estas alterações estão associadas ao diagnóstico de células escamosas atípicas de significado indeterminado e de LSIL escamosa de baixo grau. Assim, este erro tem menor impacto negativo devido ao alto percentual de regressão espontânea das lesões associadas ${ }^{22,23}$. Por outro lado, esses diagnósticos limítrofes podem apresentar maior variabilidade entre observadores devido à interpretação subjetiva de seus aspectos qualitativos e quantitativos ${ }^{12,24}$.

Neste estudo a presença de células metaplásicas atuou como fator associado a menor freqüência de resultados FN, o que não foi observado para as células endocervicais. A presença desses dois tipos celulares é considerada um indicador importante da qualidade do esfregaço, razão pela qual é imperativa a coleta da amostra do canal cervical ${ }^{25}$. Sabe-se que a presença de células metaplásicas atípicas no esfregaço citopatológico, principalmente as imaturas, está associada a alto valor preditivo para o diagnóstico de $\mathrm{HSIL}^{26}$. Este fato sugere que a zona de transformação, em especial a junção escamo-colunar, deve ser objeto de especial atenção no momento da coleta, pois é a 
área do colo uterino onde se concentram as células metaplásicas. Este cuidado deve ser observado independentemente do método do exame citopatológico, se convencional ou em meio líquido ${ }^{27}$.

Em resumo, a maioria dos fatores associados à liberação de um resultado FN é dependente das condições de coleta, pois, em grande parte, a lesão pode não estar adequadamente representada no esfregaço, assim como de fatores que obscurecem o mesmo, tais como quantidade excessiva de sangue e processo inflamatório intenso, prejudicando a análise.

Conforme o Sistema Bethesda e a recomendação do Ministério da Saúde estabeleceram, o laudo citopatológico do esfregaço do colo uterino deve conter informações sobre a adequabilidade da amostra, e a coleta deve ser repetida sempre que necessário ${ }^{7,28}$. Os laboratórios de citopatologia também poderiam, periodicamente, emitir um relatório consolidado dos exames citopatológicos de cada profissional, descrevendo aspectos relacionados a adequabilidade da amostra dos exames que coletaram. Indicadores de qualidade deveriam ser estabelecidos para orientar e indicar quando a técnica de coleta adotada precisar de revisão. Pouco pode ser feito no laboratório, em termos de redução de resultados FN, quando uma lesão presente no colo uterino não está adequadamente representada no esfregaço citopatológico.

\section{Referências}

1. Gill GW. Blinded review of Papanicolaou smears. Cancer. 2005;105(2):53-5.

2. Vizcaino AP, Moreno V, Bosch FX, Muñoz N, Barros-Dios XM, Borras $\mathrm{J}$, et al. International trends in incidence of cervical cancer: II. Squamous-cell carcinoma. Int J Cancer. 2000;86(3):429-35.

3. Hanselaar AG. Criteria for organized cervical screening programs. Special emphasis on the Netherlands program. Acta Cytol. 2002;46(4):619-29.

4. Mitchell H, Medley G. Differences between Papanicolaou smears with correct and incorrect diagnoses. Cytopathology. 1995;6(6):368-75.

5. O'Sullivan JP, A`Hern RP, Chapman PA, Jenkins L, Smith R, al-Nafussi A, et al. A case-control study of true-positive versus false-negative cervical smears in women with cervical intraepithelial neoplasia (CIN) III. Cytopathology. 1998;9(3):155-61.

6. Phadnis SV, Doshi JS, Ogunnaike OO, Padwick M, Sanusi FA. Inadequate cervical smear: what do we do? Acta Obstet Gynecol Scand. 2005;84(5):486-8.

7. Solomon D, Nayar R. Sistema Bethesda para citopatologia cervicovaginal. $2^{\text {rd }}$ ed. Rio de Janeiro: Revinter; 2005.
8. Mintzer M, Curtis P, Resnick JC, Morrell D. The effect of the quality of Papanicolaou smears on the detection of cytologic abnormalities. Cancer. 1999;87(3):113-7.

9. DeMay RM. Commom problems in Papanicolaou smear interpretation. Arch Pathol Lab Med. 1997;121(3):229-38.

10.Bosch MM, Rietveld-Scheffers PE, Boon ME. Characteristics of false negative smears tested in the normal screening situation. Acta Cytol. 1992;36(5):711-6.

11.Amaral RG, Zeferino LC, Hardy E, Westin MC, Martinez EZ, Montemor EB. Quality assurance in cervical smears: $100 \%$ rapid rescreening vs. $10 \%$ random rescreening. Acta Cytol. 2005;49(3):244-8.

12. Stoler MH, Schiffman M; Atypical Squamous Cells of Undetermined Significance-Low-grade Squamous Intraepithelial Lesion Triage Study (ALTS) Group. Interobserver reproducibility of cervical cytologic and histologic interpretations: realistic estimates from the ASCUS-LSIL Triage Study. JAMA. 2001;285(11):1500-5.

13.Torres JC, Derchain SF, Gontijo RC, do Amaral Westin MC, Zeferino LC, Angelo-Andrade LA, et al. Atypical glandular cells: criteria to discriminate benign from neoplastic lesions and squamous from glandular neoplasia. Cytopathology. 2005;16(6):295-302.

14.Hosmer DW Jr, Lemeshow S. Applied logistic regression. $2^{\text {nd }}$ ed. New York: John Wiley \& Sons; 2000.

15.Fremont-Smith M, Marino J, Griffin B, Spencer L, Bolick D. Comparison of the SurePath liquid-based Papanicolaou smear with the conventional Papanicolaou smear in a multisite direct-to-vial study. Cancer. 2004;102(5):269-79.

16.Karnon J, Peters J, Platt J, Chilcott J, McGoogan E, Brewer N. Liquid-based cytology in cervical screening: an updated rapid and systematic review and economic analysis. Health Technol Assess. 2004;8(20):1-78.

17.Davey E, Barratt A, Irwig L, Chan SF, Macaskill P, Mannes $P$, et al. Effect of study design and quality on unsatisfactory rates, cytology classifications, and accuracy in liquid-based versus conventional cervical cytology: a systematic review. Lancet. 2006;367(9505):122-32.

18.Longatto Filho A, Pereira SM, Di Loreto C, Utagawa ML, Makabe S, Maeda MY, et al. DCS liquid-based system is more effective than convencional smears to diagnosis of cervical lesions: study in high-risk population with biopsy-based confirmation. Gynecol Oncol. 2005;97(2):497-500.

19.Utagawa ML, Pereira SMM, Longatto Filho A, Martins CR, Aguiar LS, Pittoli JE, et al. Citologia de base líquida associada à captura de híbridos para DNA-HPV pode otimizar a qualidade diagnóstica do método de Papanicolaou? Rev Inst Adolfo Lutz. 2004;63(1):100-3.

20.Pereira SMM, Utagawa ML, Pittoli JE, Aguiar LS, Maeda MYS, Longatto Filho A, et al. Avaliação da ce- 
lularidade citológica em preparados de base líquida. Rev Inst Adolfo Lutz. 2003;62(1):35-9.

21.De May RM. The art \& science of cytopathology exfoliative cytology. Chicago: ASCP Press; 1996.

22.Östor AG. Natural history of cervical intraepithelial neoplasia: a critical review. Int $\mathrm{J}$ Gynecol Pathol. 1993;12(2):186-92.

23. Moscicki AB, Shiboski S, Hills NK, Powell KJ, Jay N, Hanson EN, et al. Regression of low-grade squamous intra-epithelial lesions in young women. Lancet. 2004;364(9446):1678-83.

24.Confortini M, Carozzi F, Dalla Palma P, Ghiringhello $\mathrm{B}$, Parisio F, Prandi S, et al. Interlaboratory reproducibility of atypical squamous cells of undetermined significance report: a national survey. Cytophatology. 2003;14(5):263-8.

25 Zeferino LC, Catharino JMR, Araújo MAS, Silva LCB,
Vedoato SR, Tambascia JK, et al. Desempenho das amostras do canal cervical e do fundo de saco no diagnóstico da neoplasia do colo uterino. Rev Bras Ginecol Obstet. 2000;22(3):129-34.

26.Dufloth RM, Messias-Silva SM, Andrade LA, di Loreto $\mathrm{C}$, Munhoz DM, Zeferino L. Nuclear alterations of the cells and atypical metaplastic cells in cervical smears are predictive criteria of high-grade cervical intraepithelial neoplasia. Eur J Gynaecol Oncol. 2005;26(2):186-90.

27. Siebers AG, de Leeuw H, Verbeek AL, Hanselaar AG. Prevalence of squamous abnormalities in women with a recent smear without endocervical cells is lower as compared to women with smears with endocervical cells. Cytopathology. 2003;14(2):58-65.

28. Ministério da Saúde. Prevenção do câncer do colo do útero. Manual técnico para laboratórios. Brasília; 2002. 